\title{
Progressive Taxation as an Automatic Stabilizer under Nominal Wage Rigidity and Preference Shocks*
}

\author{
Miroslav Gabrovski \\ University of Hawaii at Manoa ${ }^{\dagger}$ \\ Jang-Ting Guo \\ University of California, Riverside
}

March 23, 2020

\begin{abstract}
Previous research has shown that in the context of a prototypical New Keynesian model, more progressive income taxation may lead to higher volatilities of hours worked and total output in response to a monetary disturbance. We analytically show that this business-cycle destabilization result is overturned within an otherwise identical macroeconomy subject to impulses to the household's utility formulation. Under a continuously or linearly progressive fiscal policy rule, an increase in the tax progressivity will always raise the degree of equilibrium nominal-wage rigidity, and thus serve as an automatic stabilizer that mitigates cyclical fluctuations driven by preference shocks. Our analysis illustrates that whether a more progressive tax schedule (de)stabilizes the business cycle depends crucially on the underlying driving source.
\end{abstract}

Keywords: Progressive Income Taxation, Automatic Stabilizer, Nominal Wage Rigidity, Preference Shocks.

JEL Classification: E12, E32, E62.

\footnotetext{
${ }^{*}$ We thank Nicolas Caramp, Juin-Jen Chang, Mingming Jiang, Yi Mao, Victor Ortego-Marti, Chong-Kee Yip, and seminar participants at Academia Sinica, Chinese University of Hong Kong, Chinese University of Hong Kong at Shenzhan, Shadong University, and National Chengchi University for helpful comments and suggestions. Part of this research was conducted while Guo was a visiting research fellow at the Institute of Economics, Academia Sinica, whose hospitality is greatly appreciated. Of course, all remaining errors are own own.

${ }^{\dagger}$ Department of Economics, University of Hawaii at Manoa, 2424 Maile Way, Saunders 516, Honolulu, HI 96822, USA; Phone: 1-808-956-7749, Fax: 1-808-956-4347, E-mail: mgabr@hawaii.edu.

${ }^{\ddagger}$ Corresponding Author. Department of Economics, 3133 Sproul Hall, University of California, Riverside, CA 92521, USA; Phone: 1-951-827-1588, Fax: 1-951-827-5685, E-mail: guojt@ucr.edu.
} 


\section{Introduction}

The business-cycle stabilization effect of progressive income taxation has been regarded as one of the central topics in macroeconomic research. In the context of a traditional Keynesian macroeconomy, an increase in the tax progressivity operates like an automatic stabilizer that will mitigate the magnitude of cyclical variations in consumption spending and total output. This conventional viewpoint is found to be also valid within one-sector real business cycle models. In particular, Guo and Lansing (1998) and Dromel and Pintus (2007) show that a more progressive fiscal policy rule may stabilize the economy against sunspot-driven macroeconomic fluctuations; whereas Schmitt-Grohé and Uribe (1997) find that equilibrium indeterminacy may arise in a standard representative-agent model with regressive income taxation. In our earlier work, Gabrovski and Guo (2019) report that these previous findings can be overturned in a prototypical New Keynesian macroeconomy, developed by Kleven and Kreiner (2003), driven by shocks to the quantity of nominal money supply. As it turns out, it is straightforward to obtain the qualitatively identical business-cycle destabilization result of more progressive taxation when ceteris paribus the Kleven-Kreiner model is subject to technological disturbances to firms' production functions. ${ }^{1}$ In this environment, either impulse leads to a shift of the labor demand curve, which in turn will affect the economy's aggregate demand/supply under a monetary/technology shock.

In this follow-up piece, we examine the robustness of Gabrovski and Guo's (2019) theoretical findings in an identical New Keynesian model, but subject to an alternative demand impulse. Specifically, shocks to the marginal utility of consumption à la Bencivenga (1992) that influence each household's urge to consume are considered. As a result, this preference disturbance enters the marginal rate of substitution between consumption and hours worked, which in turn will cause the labor supply curve to shift. Under either (i) Guo and Lansing's (1998) continuously progressive tax schedule, or (ii) Dromel and Pintus' (2007) piece-wise linearly progressive fiscal police rule, we obtain exactly the opposite result to that in Gabrovski and Guo (2019). That is, as in traditional Keynesian macroeconomics, more progressive income taxation is found to dampen cyclical fluctuations driven by impulses to an agent's utility function. The key insight is that although both preference and monetary disturbances affect the economy's aggregate demand, they will generate very different effects in the labor market: a preference shock shifts the household's labor supply curve, whereas a monetary shock shifts the firm's labor demand curve. In sum, our two papers altogether illustrate that whether a more progressive fiscal policy rule (de)stabilizes the Kleven-Kreiner macroeconomy depends crucially on the driving source of business cycles.

\footnotetext{
${ }^{1}$ The derivation details for this finding are available upon request.
} 
Under the Guo-Lansing fiscal policy formulation, we analytically find that the economy always exhibits a higher degree of equilibrium nominal-wage rigidity when the tax schedule becomes more progressive. ${ }^{2}$ Intuitively, start the model with a given tax progressivity and consider a positive preference shock that shifts the labor supply curve to the right. Regardless of how an individual household responds by maintaining or changing its nominal wage, the resulting nominal income is shown to be the same. In addition, when agents decide to adjust nominal wages, their real labor income will be higher because of a decrease in the aggregate output price index. Next, consider an increase in the tax progressivity that raises the symmetric-equilibrium marginal tax rate. Given the aforementioned discussion, each "adjusting" household's after-tax real wage income may increase or decrease as the tax-slope parameter rises. Our analysis proves that more progressive taxation will reduce the utility loss from non-adjustment of nominal wages, because the effect of a higher marginal tax rate outweighs the opposite impact of an augment in the real income under all feasible parametric configurations. Consequently, agents are less capable of paying the adjustment cost needed for changing their nominal wages, which in turn will enhance the likelihood of fixed nominal wages in equilibrium.

We also find that upon a positive disturbance to the household's marginal utility of consumption, there will be no variability in hours worked when the initial equilibrium nominal wage remains unchanged. On the other hand, when agents decide to decrease their nominal wages because of a lower disutility from working, the new equilibrium will exhibit a higher level of labor hours. Based on the combined results from this and the preceding paragraphs, a reduction in the economy's equilibrium degree of nominal-wage rigidity, captured by an increase in the loss of utility from non-adjustment, will raise the volatilities in hours worked and thus total output. It follows that consistent with the traditional stabilization view, Guo and Lansing's (1998) continuously progressive tax system always serves as an automatic stabilizer against aggregate fluctuations driven by preference shocks within our New Keynesian model.

Under the Dromel-Pintus fiscal policy formulation, we analytically show that the utility loss from non-adjustment when the marginal tax rate is positive is lower than that with no income taxation because households are less able to pay the requisite menu cost in the former case, hence fixed nominal wages are more likely to occur. This result can be extended to a setting that considers two distinct positive levels of marginal tax rates. Accordingly, the economy will exhibit a higher degree of equilibrium nominal-wage rigidity as the tax progressivity (an increasing function of the marginal tax rate) rises. Per the labor-market analysis described

\footnotetext{
${ }^{2}$ By contrast, Gabrovski and Guo (2019, Proposition 2) obtain a sufficient condition under which a higher tax progressivity à la Guo and Lansing's (1998) formulation may raise the likelihood of fixed nominal wages in equilibrium when the same macroeconomy is driven by monetary shocks.
} 
above, the variations of labor hours and total output are relatively higher under fully-adjusted nominal wages. It follows that in accordance with the conventional Keynesian viewpoint, Dromel and Pintus' (2007) piece-wise linearly progressive tax system also always operates like an automatic stabilizer against preference-shock-driven business cycles within the KlevenKreiner macroeconomy. In terms of value added, our findings are worthwhile not only for their theoretical insights to the academic literature, but also for their important implications about the stabilization effect of progressive tax policies in the context a prototypical New Keynesian model.

The remainder of this paper is organized as follows. Section 2 describes our New Keynesian macroeconomy subject to preference shocks, discusses its equilibrium conditions, and then analytically examines the interrelations between equilibrium nominal-wage rigidity versus business-cycle stabilization under continuously progressive income taxation. Section 3 studies the same macroeconomy under piece-wise linearly progressive taxation. Section 4 concludes.

\section{The Economy}

As in Kleven and Kreiner (2003) and Gabrovski and Guo (2019), the economy is populated by three types of agents: households, firms, and the government. There is a unit measure of households who derive utility from leisure and their consumption basket of a continuum of differentiated goods that are subject to preference shocks. Each household provides a distinct variety of hours worked to a monopolistically competitive labor market; and faces a cash-inadvance constraint on its consumption expenditures. On the production side of the economy, a unit mass of monopolistically competitive firms produce differentiated consumption goods with a technology that uses labor as the sole input under decreasing returns-to-scale. The government levies labor income taxation through a continuously progressive tax schedule $\grave{a}$

la Guo and Lansing (1998), and distributes its revenue back to households in the form of lump-sum transfers. To facilitate comparison with Gabrovski and Guo (2019), output prices are postulated to be fully flexible and other forms of taxation are not considered.

\subsection{Households}

Within our model economy, there is a continuum of households that are uniformly distributed over $[0,1]$ and indexed by $i$. Household $i$ supplies a differentiated labor input, denoted as $l_{i}$, and consumes a basked of goods that firms indexed by $j \in[0,1]$ produce. The utility function for household $i$ is given by 


$$
u_{i}=\Lambda \underbrace{\left(\int_{0}^{1} c_{i j}^{1-\mu} d j\right)^{\frac{1}{1-\mu}}}_{\equiv C_{i}}-\frac{\gamma}{1+\gamma} l_{i}^{\frac{1+\gamma}{\gamma}}, \quad 0<\mu<1, \quad \Lambda \text { and } \gamma>0
$$

where $c_{i j}$ is the consumption of variety $j$ by household $i, C_{i}$ is the consumption basket, $\mu$ is the inverse of the elasticity of substitution between two distinct consumption goods, and $\gamma$ is the Frisch elasticity of labor supply. Moreover, $\Lambda$ is a random shock to preferences that affects the household's marginal utility of consumption à la Bencivenga (1992). In particular, an increase in $\Lambda$ represents a positive disturbance to the economy's aggregate demand as it raises agents' urge to consume.

In a monopolistically competitive labor market, household $i$ selects the nominal wage $w_{i}$ for its labor service. Its gross nominal labor income is $w_{i} l_{i}$, which will be taxed at a rate of $t_{i} \in(0,1)$. Household $i$ also receives a share of firm $j$ 's profit in the form of dividends $\pi_{i j}$; as well as lump-sum transfer payments from the government in the amount of $S_{i}=\int_{0}^{1} \tau_{i} w_{i} l_{i} d i$ under the maintained assumption of a balanced budget. It follows that the budget constraint faced by household $i$ is

$$
\int_{0}^{1} p_{j} c_{i j} d j=\left(1-t_{i}\right) w_{i} l_{i}+\int_{0}^{1} \pi_{i j} d j+S_{i}
$$

where $p_{j}$ is the market price for variety $j$.

We postulate that the tax scheme is continuously progressive in the spirit of Guo and Lansing (1998), hence the tax rate $t_{i}$ is specified as

$$
t_{i}=\eta\left(\frac{w_{i} l_{i}}{w l}\right)^{\phi}, \quad 0<\eta<1, \quad 0<\phi<1
$$

where $w l=\int_{0}^{1} w_{i} l_{i} d i$ is the average level of nominal wage income across all households, and the parameters $\eta$ and $\phi$ govern the level and slope (or elasticity) of the tax schedule, respectively. As in much of the previous literature, households are able to to rationally anticipate the way in which changes to their income affect their tax burden. As a result, each household's economic decisions are governed by its individual marginal tax rate given by

$$
t_{i}^{m}=\frac{\partial\left(t_{i} w_{i} l_{i}\right)}{\partial\left(w_{i} l_{i}\right)}=\eta(1+\phi)\left(\frac{w_{i} l_{i}}{w l}\right)^{\phi} .
$$

Our analysis below will focus on an environment in which households have an incentive to provide labor services and the government cannot confiscate productive resources, hence $0<t_{i}$, $t_{i}^{m}<1$ is imposed. At the model's symmetric equilibrium with $w_{i}=w$ and $l_{i}=l$ for all $i$, these conditions imply that $\eta \in(0,1)$ and $\phi \in\left(-1, \frac{1-\eta}{\eta}\right)$, where $\frac{1-\eta}{\eta}>0$. It follows that 
when $\phi>(<) 0$, the tax schedule is said to be progressive (regressive), i.e. the marginal tax rate is higher (lower) than the corresponding average tax rate given by $(3)$. When $\phi=0$, the average and marginal tax rates coincide at the constant level of $\eta$, thus the tax scheme is flat. Consequently, the degree of tax progressivity associated with (3) is determined by the elasticity parameter $\phi$. We also note that per the observed progressive U.S. federal individual income tax schedule, the listed statutory marginal tax rate $t_{i}^{m}$ is an increasing and concave function with respect to taxable-income $\left(w_{i} l_{i}\right)$ brackets. Hence, the tax-progressivity parameter is further restricted to the interval $0<\phi<1$.

In addition to the budget constraint (2), household $i$ faces a cash-in-advance (CIA) constraint whereby all consumption purchases must be financed by its nominal money holdings $M_{i}$ :

$$
\int_{0}^{1} p_{j} c_{i j} d j \leq M_{i}
$$

Without loss of generality, the economy's aggregate level of nominal money balance is nor-

malized to be one, i.e. $\int_{0}^{1} M_{i} d i=1$. Taking aggregation over each household's first-order condition with respect to $c_{i j}$ yields that the total demand for consumption good $j$ is given by

$$
c_{j}=\int_{0}^{1} c_{i j} d i=\left(\frac{p_{j}}{P}\right)^{-\frac{1}{\mu}} \frac{1}{P}, \quad \text { where } P=\left(\int_{0}^{1} p_{j}^{\frac{\mu-1}{\mu}}\right)^{\frac{\mu}{\mu-1}}
$$

denotes the aggregate price index for the consumption basket.

\section{$2.2 \quad$ Firms}

The economy's production side consists of a unit mass of firms that are distributed uniformly over $[0,1]$. Each firm $j$ produces a differentiated output $y_{j}$ with varieties of labor as the inputs under decreasing returns-to-scale given by

$$
y_{j}=\frac{1}{\alpha}\left(\int_{0}^{1} l_{i j}^{1-\rho} d i\right)^{\frac{\alpha}{1-\rho}}, \quad 0<\alpha, \rho<1,
$$

where $\rho$ is the inverse of the elasticity of substitution between labor hours supplied by two distinct households, and $\alpha$ governs the concavity of the production function. The first-order condition for firm $j$ 's wage-cost minimization problem leads to the following demand function for labor of type $i$ :

$$
l_{i j}=\left(\frac{w_{i}}{W}\right)^{-\frac{1}{\rho}}\left(\alpha y_{j}\right)^{\frac{1}{\alpha}}, \quad \text { where } W=\left(\int_{0}^{1} w_{i}^{\frac{\rho-1}{\rho}} d i\right)^{\frac{\rho}{\rho-1}}
$$


is the aggregate nominal-wage index. Using this optimality condition (8), together with the consumption demand function (6), we find that the indirect profit function for firm $j$ can be expressed as

$$
\pi_{j}=\left(\frac{p_{j}}{P}\right)^{-\frac{1-\mu}{\mu}}-W\left(\frac{p_{j}}{P}\right)^{-\frac{1}{\alpha \mu}}\left(\frac{\alpha}{P}\right)^{\frac{1}{\alpha}}
$$

which will be returned to households as lump-sum dividends. From the first-order condition of maximizing (9), it can be shown that the output price $p_{j}$ is set according to

$$
\frac{p_{j}}{P}=\left[\frac{1}{1-\mu} \frac{W}{P}\left(\frac{\alpha}{P}\right)^{\frac{1-\alpha}{\alpha}}\right]^{\frac{\alpha \mu}{\alpha \mu+1-\alpha}} \text {. }
$$

\subsection{Symmetric Equilibrium}

Using the household's budget constraint (2) and the demand function for consumption goods (6), we can rewrite household $i$ 's utility function (1) as

$$
u_{i}=\Lambda\left[\frac{\left(1-t_{i}\right) w_{i} l_{i}}{P}+\int_{0}^{1} \frac{\pi_{i j}}{P} d j+\frac{S_{i}}{P}\right]-\frac{\gamma}{1+\gamma} l_{i}^{\frac{1+\gamma}{\gamma}} .
$$

Substituting the labor demand condition (8) into the above equation yields the following indirect utility function:

$$
V\left(w_{i}, \Lambda\right)=\Lambda\left[\frac{\left(1-t_{i}\right) w_{i}}{P}\left(\frac{w_{i}}{W}\right)^{-\frac{1}{\rho}}\left(\frac{\alpha}{P}\right)^{\frac{1}{\alpha}}+\int_{0}^{1} \frac{\pi_{i j}}{P} d j+\frac{S_{i}}{P}\right]-\frac{\gamma}{1+\gamma}\left[\left(\frac{w_{i}}{W}\right)^{-\frac{1}{\rho}}\left(\frac{\alpha}{P}\right)^{\frac{1}{\alpha}}\right]^{\frac{1+\gamma}{\gamma}}
$$

At the model's symmetric equilibrium with $w_{i}=w, l_{i}=l$, and $t_{i}^{m}=t^{m}$ for all $i$, it is straightforward to show that the first-order condition of maximizing (12) leads to the optimal nominal wage $w_{i}$ given by

$$
\frac{w_{i}}{W}=\left\{\Lambda(1-\rho)[1-\underbrace{\eta(1+\phi)}_{=t^{m}}] \frac{W}{P}\right\}^{-\frac{\gamma \rho}{1+\gamma \rho}}\left(\frac{\alpha}{P}\right)^{\frac{\rho}{\alpha(1+\gamma \rho)}} .
$$

\subsection{Nominal Wage Rigidity and Business Cycle Stabilization}

The main objective of our analysis is to examine theoretical interrelations between the level of tax progressivity versus (i) the degree of equilibrium nominal-wage rigidity, and (ii) the magnitude of fluctuations in labor hours (and thus output) resulting from an aggregate demand disturbance. As in Kleven and Kreiner (2003), Gabrovski and Guo (2019) and many previous New Keynesian studies, we postulate that households must pay a lump-sum cost of adjustment 
$F>0$ when they decide to change their nominal wages following a preference shock denoted as $d \Lambda$. Let $V^{A}$ and $V^{N}$ be the associated utility levels under flexible (or fully adjusted) and fixed nominal wages, respectively. It follows that $\Delta V \equiv V^{A}-V^{N}$ represents the loss of utility from non-adjustment of nominal wages.

Taking a second-order Taylor expansion on the household's indirect utility function (12) around the model's initial symmetric equilibrium yields that

$$
\Delta V \approx V_{12} d w_{i} d \Lambda+\frac{1}{2} V_{11}\left(d w_{i}\right)^{2}
$$

where $V_{12}=\frac{\partial^{2} V}{\partial w_{i} \partial \Lambda}$ and $V_{11}=\frac{\partial^{2} V}{\partial w_{i}^{2}} \cdot{ }^{3}$ Using equations (10), (12) and (13), we can then obtain the analytical expression of $\Delta V$ as follows:

$$
\Delta V=\frac{\gamma\{\Lambda(1-\rho)(1-\mu)[1-\eta(1+\phi)]\}^{\frac{1+\gamma}{1+\gamma(1-\alpha)}}}{2(1+\gamma \rho)\left[1+\frac{\gamma \eta \phi(1-\rho)(1+\phi)}{(1+\gamma \rho)[1-\eta(1+\phi)]}\right]}\left(\frac{d \Lambda}{\Lambda}\right)^{2}>0
$$

because of $0<\alpha, \mu, \rho, \eta, \phi, \eta(1+\phi)<1$ and $\gamma, \Lambda>0$. Hence, in response to an aggregate demand shock $d \Lambda$, households will adjust their nominal wages if and only if $\Delta V$ exceeds the requisite menu cost $F$. Moreover, a decrease in the utility loss of non-adjustment $\Delta V$ will enhance the likelihood of fixed nominal wages, hence raising the equilibrium degree of nominal-wage rigidity within our model economy.

Proposition 1. Under a preference shock $d \Lambda$ and continuously progressive income taxation, an increase in the tax progressivity will always lead to a higher degree of equilibrium nominal-wage rigidity, i.e. $\frac{\partial(\Delta V)}{\partial \phi}<0$.

Proof. After taking partial differentiation on (15), it can be shown that

$$
\frac{\partial \Delta V}{\partial \phi}=-\Delta V\left\{\Omega+\frac{\gamma \eta(1-\rho)(1+\gamma \rho)\{\phi+(1+\phi)[1-\eta(1+\phi)]\}}{(1+\gamma \rho)[1-\eta(1+\phi)]\{(1+\gamma \rho)[1-\eta(1+\phi)]+\gamma \eta \phi(1-\rho)(1+\phi)\}}\right\}
$$

where $\Omega=\frac{\eta(1+\gamma)}{[1+\gamma(1-\alpha)][1-\eta(1+\phi)]}$. Since $0<\alpha, \rho, \eta, \phi, \eta(1+\phi)<1$ and $\gamma>0$, both terms inside the curly brackets on the right hand side of (16) are strictly positive. This result, together with $\Delta V>0$ per equation (15), yields that $\frac{\partial \Delta V}{\partial \phi}<0$.

The intuition for this Proposition can be understood from Figure 1. Consider the labor market that begins at the initial symmetric equilibrium $E^{*}$ under a given (positive) level of

\footnotetext{
${ }^{3}$ These approximations follow from

$$
\begin{gathered}
V^{A} \approx V^{0}+V_{1} d w_{i}+V_{2} d \Lambda+\frac{1}{2} V_{11}\left(d w_{i}\right)^{2}+\frac{1}{2} V_{22}(d \Lambda)^{2}+V_{12} d w_{i} d \Lambda \\
\text { and } V^{N} \approx V^{0}+V_{2} d \Lambda+\frac{1}{2} V_{22}(d \Lambda)^{2}
\end{gathered}
$$

where $V^{0}$ is the indirect utility function evaluated at the model's initial symmetric equilibrium.
} 
tax progressivity. Upon a positive preference shock that raises $\Lambda$, each household values its consumption basket more as the resulting marginal utility is now higher. This in turn reduces the marginal rate of substitution between consumption and hours worked given by $\frac{l^{1 / \gamma}}{\Lambda}$, which will then generate a rightward shift of the labor supply curve. Figure 1 shows that if households decide to adjust their wages, the new symmetric equilibrium is located at $E^{\prime}$ characterized by a lower nominal wage $w^{\prime}$ and a higher level of labor hours $l^{\prime}$. It follows that whether the household's nominal income increases or decreases as a result of nominal-wage adjustments is theoretically ambiguous.

In order to answer this question, we first combine equations (10) and (13) to find that in response to an utility impulse, the percentage change in the fully-flexible aggregate price index is given by

$$
\frac{d P / P}{d \Lambda / \Lambda}=-\frac{\alpha \gamma}{1+\gamma(1-\alpha)}<0
$$

Next, using (10) and (17) shows that the corresponding response of symmetric-equilibrium nominal wages (falling from $w^{*}$ to $w^{\prime}$ ) is

$$
\frac{d w / w}{d \Lambda / \Lambda}=-\frac{\gamma}{1+\gamma(1-\alpha)}<0
$$

Finally, combining (8), (13) and (17)-(18) yields that the symmetric-equilibrium labor hours will change (rising from $l^{*}$ to $l^{\prime}$ ) according to

$$
\frac{d l / l}{d \Lambda / \Lambda}=\frac{\gamma}{1+\gamma(1-\alpha)}>0
$$

Equations (18) and (19) together indicate that when households decide to adjust their wages after a preference shock takes place, the equilibrium nominal wages and hours worked will move in the opposite direction and by the same percentage. It follows that their nominal income remains unchanged, i.e. $w^{*} l^{*}=w^{\prime} l^{\prime}$. Moreover, since the resulting equilibrium output prices become lower à la (17), each "adjusting" agent's $\left(=\frac{w l}{P}\right)$ real wage income will be higher as a consequence. When households decide not to change nominal wages upon an utility disturbance, their nominal as well as real labor income will remain unaffected.

On the other hand, when the tax schedule becomes more progressive, the symmetricequilibrium marginal tax rate $\eta(1+\phi)$ will be higher. This outcome, together with the preceding discussion, implies that the after-tax real income $\left(1-t^{m}\right) \frac{w l}{P}$ when each agent adjusts its nominal wage may increase or decrease as the tax-elasticity parameter $\phi$ rises under a preference shock. Proposition 1 analytically shows that more progressive taxation will always reduce the utility loss from non-adjustment of nominal wages, i.e. $\frac{\partial(\Delta V)}{\partial \phi}<0$, because the effect of a 
higher marginal tax rate outweighs the opposite impact of an augment in the household's real labor income under all feasible parametric configurations. As a result, agents are less capable of paying the adjustment cost $F$ needed for changing their nominal wages, which in turn raises the economy's equilibrium degree of nominal-wage rigidity.

Proposition 2. Under a preference shock $d \Lambda$ and continuously progressive income taxation, an increase in the tax progressivity will generate lower volatilities in labor hours and output.

The underlying intuition for this Proposition is straightforward. In response to a positive preference shock, households can either pay the menu cost $F$ and adjust their wages or keep them fixed. Figure 1 shows that if the nominal wage remains unchanged with its initial equilibrium level $w^{*}$, then there is no variability in hours worked at $l^{*}$. As a result, $\frac{d l / l}{d \Lambda / \Lambda}=0$ under fixed nominal wages. By contrast, if households decide to decrease their wages to $w^{\prime}$ because of a lower disutility from working, the new equilibrium $E^{\prime}$ will exhibit a higher level of labor hours $l^{\prime}$. It follows that as shown in (19), $\frac{d l / l}{d \Lambda / \Lambda}>0$ under flexible nominal wages. The above results jointly imply that a reduction in the economy's degree of equilibrium nominalwage rigidity, captured by an increase in the utility loss from non-adjustment $\Delta V$, will raise the volatilities in hours worked and thus output, i.e. $\frac{\partial\left(\frac{d l / l}{d \Lambda / \Lambda}\right)}{\partial(\Delta V)}>0$.

Accordingly, we can use the chain rule to decompose the overall effect of a tax-progressivity change on the magnitude of cyclical fluctuations as follows:

$$
\frac{\partial\left(\frac{d l / l}{d \Lambda / \Lambda}\right)}{\partial \phi}=\underbrace{\frac{\partial\left(\frac{d l / l}{d \Lambda / \Lambda}\right)}{\partial(\Delta V)}}_{\text {Positive }} \underbrace{\frac{\partial(\Delta V)}{\partial \phi}}_{\text {Negative }}<0
$$

where $\frac{\partial(\Delta V)}{\partial \phi}<0$ is taken from Proposition 1. Therefore, equation (20) states that more progressive income taxation will lead to lower variations of macroeconomic aggregates within our model economy. In sum, this section finds that Guo and Lansing's (1998) continuously progressive tax policy always operates like an automatic stabilizer against business cycles driven by impulses to the household's consumption basket.

To gain further insights, it is worth emphasizing that Proposition 2 delivers exactly the opposite result to that in Gabrovski and Guo (2019) when the same model is subject to monetary shocks given by $d M$, where $M=\int_{0}^{1} M_{i} d i$ denotes the total quantity of nominal money supply. As illustrated in Figure 2, a positive monetary disturbance that increases the economy's aggregate demand will shift the labor demand curve to the right. When households decide to maintain wages at the initial level $w^{*}$, their labor hours are raised to $l^{\prime \prime}$, which is higher than $l^{\prime}$ under flexible nominal wages. It follows that the economy displays a relatively 
higher output volatility when nominal wages are fixed. On the contrary, Figure 1 shows that a positive preference impulse $d \Lambda$ causes a rightward shift of the labor supply curve and thus there will be no fluctuations in hours worked under fixed nominal wages. Since an increase in the tax progressivity can lead to a higher degree of equilibrium nominal-wage rigidity in both settings (see Proposition 1 versus footnote 2), the Guo-Lansing continuously progressive fiscal policy rule destabilizes/stabilizes the business cycle driven by monetary/preference shocks within our New Keynesian macroeconomy.

\section{Linearly Progressive Taxation}

In this section, we adopt Dromel and Pintus' (2007) piece-wise linearly progressive tax formulation and then analytically examine its stabilization effects within the New Keynesian macroeconomy described in section 2. The budget constraint faced by the representative household is modified to

$$
\int_{0}^{1} p_{j} c_{i j} d j=w_{i} l_{i}-\underbrace{\tau\left(w_{i} l_{i}-E\right)}_{\text {Tax Payment }}+\int_{0}^{1} \pi_{i j} d j+S_{i},
$$

where $E>0$ represents the exemption level of income. The government is postulated to impose a positive tax rate $\tau \in(0,1)$ on the fraction of agent $i$ 's wage income $w_{i} l_{i}$ that is strictly higher than the pre-specified threshold $E$; and $\tau=0$ when $w_{i} l_{i} \leq E$. This parsimonious two-incomebracket specification is able to qualitatively capture the piecewise linear feature commonly observed in real world tax systems. In addition, the tax schedule under consideration is progressive when $w_{i} l_{i}>E$, since the resulting average tax rate $A T R_{i}=\tau\left(1-\frac{E}{w_{i} l_{i}}\right)$ is lower than the (constant) marginal tax rate $M T R_{i}=\tau$. We also follow Dromel and Pintus (2007) and define the degree of tax progressivity on household $i$ as

$$
\theta_{i} \equiv \frac{M T R_{i}-A T R_{i}}{1-A T R_{i}}=\frac{\tau E}{(1-\tau) w_{i} l_{i}+\tau E}, \quad \text { where } \frac{\partial \theta_{i}}{\partial \tau}>0 \text { and } \frac{\partial \theta_{i}}{\partial E}>0,
$$

i.e. an increase in either the marginal tax rate $\tau$ or the threshold income level $E$ will lead to a more progressive fiscal policy rule. As in the preceding section, we maintain the assumption that the household's economic decisions are governed by its marginal tax rate; hence our analysis below is restricted to an environment with $\tau \in(0,1)$.

Next, we follow the same solution procedure of sections 2 to show that under linearly progressive income taxation, (i) the equilibrium conditions that characterize the aggregate demand and market price for consumption good $j$, as in equations (6) and (10), will remain the same; (ii) the indirect utility function for household $i$ now becomes 


$$
\hat{V}\left(w_{i}, \Lambda\right)=\Lambda\left[\frac{(1-\tau) w_{i}}{P}\left(\frac{w_{i}}{W}\right)^{-\frac{1}{\rho}}\left(\frac{\alpha}{P}\right)^{\frac{1}{\alpha}}+\frac{\tau E+\int_{0}^{1} \pi_{i j} d j+S_{i}}{P}\right]-\frac{\gamma}{1+\gamma}\left[\left(\frac{w_{i}}{W}\right)^{-\frac{1}{\rho}}\left(\frac{\alpha}{P}\right)^{\frac{1}{\alpha}}\right]^{\frac{1+\gamma}{\gamma}}
$$

where $P$ and $W$ are given by (6) and (8), respectively; (iii) at the model's symmetric equilibrium with $w_{i}=w, l_{i}=l$, and thus $\theta_{i}=\theta$ for all $i$, household $i$ 's nominal wage $w_{i}$ is set according to

$$
\frac{w_{i}}{W}=\left[\Lambda(1-\rho)(1-\tau) \frac{W}{P}\right]^{-\frac{\gamma \rho}{1+\gamma \rho}}\left(\frac{\alpha}{P}\right)^{\frac{\rho}{\alpha(1+\gamma \rho)}}
$$

and (iv) the utility loss from non-adjustment of nominal wages in response to a preference shock $d \Lambda$ is

$$
\Delta \hat{V} \equiv \hat{V}^{A}-\hat{V}^{N}=\frac{\gamma[\Lambda(1-\rho)(1-\mu)(1-\tau)]^{\frac{1+\gamma}{1+\gamma(1-\alpha)}}}{2(1+\gamma \rho)}\left(\frac{d \Lambda}{\Lambda}\right)^{2}>0
$$

because of $0<\alpha, \mu, \rho, \tau<1$ and $\gamma, \Lambda>0$.

To compare the required level of adjustment costs for keeping nominal wages unchanged under two distinct values of $\tau$ at the model's initial symmetric equilibrium, we use equation (25) to derive that

$$
\Delta \hat{V}(\tau>0)-\Delta \hat{V}(\tau=0)=\underbrace{\left\{\frac{\gamma[\Lambda(1-\rho)(1-\mu)]^{\frac{1+\gamma}{1+\gamma(1-\alpha)}}}{2(1+\gamma \rho)}\left(\frac{d \Lambda}{\Lambda}\right)^{2}\right\}}_{\text {positive }}\left[(1-\tau)^{\frac{1+\gamma}{1+\gamma(1-\alpha)}}-1\right]<0 .
$$

As in the preceding section, since a relatively smaller loss of utility from non-adjustment $\Delta \hat{V}$ enlarges the parametric space that exhibits nominal-wage rigidity, equation (26) shows that the presence of positive income taxation will enhance the likelihood of fixed nominal wages in equilibrium. It is then straightforward to obtain the following:

Proposition 3. Under a preference shock $d \Lambda$ and (piece-wise) linearly progressive income taxation, an increase in the tax progressivity will always (i) raise the degree of equilibrium nominal-wage rigidity, and (ii) operate like an automatic stabilizer that yields lower volatilities in labor hours and output.

Using the earlier discussions associated with Figure 1 to examine our model under no income taxation, as a positive preference shock shifts the labor supply curve to the right, the household's nominal income will remain unchanged $\left(w^{*} l^{*}=w^{\prime} l^{\prime}\right)$ regardless of whether its nominal wage is adjusted or not. This result, together with a decrease in the aggregate price index as shown in (17), leads to an increase in the real wage income. Since agents receive the 
full amount of their labor income when $\tau=0$, they will be more able to pay the adjustment cost $F$ needed for changing nominal wages. On the contrary, fully-flexible nominal wages are less likely to occur under positive income taxation with $\tau>0$ because the household's disposable wage income is now lower. The above intuitive explanations can be extended to a setting that considers two different positive levels of $\tau$. Specifically, it can be shown that the utility loss $\Delta \hat{V}$ will be smaller in an economy with a higher marginal tax rate, hence agents are more likely to keep their initial nominal wages in response to a preference disturbance. In sum, the negative income effect associated with a higher tax rate will reduce households' ability to adjust their nominal wages.

Next, it is straightforward to show that an increase in the marginal tax rate will decrease the magnitude of business cycle fluctuations. The intuition for this finding is the same as in Proposition 2. Figure 1 depicts that when agents decide not to change their nominal wages upon a positive utility impulse, the equilibrium labor hours remain unaffected $\left(\frac{d l / l}{d \Lambda / \Lambda}=0\right)$; and that when the nominal wage is adjusted to fall, the household also increases its labor supply $\left(\frac{d l / l}{d \Lambda / \Lambda}>0\right)$ and thus produce more output. Based on the preceding paragraph which illustrates that fixed nominal wages are more likely to take place under a higher marginal tax rate, the economy will exhibit lower volatilities in hours worked and total output as a consequence. Finally, since the symmetric-equilibrium tax progressivity $\theta$ is ceteris paribus monotonically increasing in $\tau$ (see equation 22), our study shows that a more (piece-wise) linearly progressive tax system always raises the equilibrium degree of nominal-wage rigidity and operates like an automatic stabilizer against cyclical fluctuations driven by preference shocks.

To summarize, this paper has overturned the business-cycle destabilization result of more progressive income taxation à la Gabrovski and Guo (2019) within the same New Keynesian model driven by impulses to the household utility ( $c f$. the quantity of nominal money supply). Under the Guo-Lansing continuously or the Drome-Pintus linearly progressive tax schedule, we analytically show that an increase in the tax progressivity will always enhance the likelihood of fixed nominal wages in equilibrium and mitigate macroeconomic fluctuations caused by preference shocks. The key insight is that although both preference and monetary disturbances affect the economy's aggregate demand, they will generate very different effects in the labor market: a preference shock shifts the household's labor supply curve (see Figure 1), whereas a monetary shock shifts the firm's labor demand curve (see Figure 2). As a result, our analysis finds that whether a more progressive fiscal policy rule (de)stabilizes the Kleven-Kreiner macroeconomy depends crucially on the driving source of business cycles. 


\section{Conclusion}

In our previous work, Gabrovski and Guo (2019) find that more progressive income taxation may operate like an automatic destabilizer which generates higher cyclical volatilities of labor hours and total output within a prototypical New Keynesian macroeconomy driven by shocks to aggregate money supply. The current paper demonstrates that this business-cycle destabilization result is not robust to a slight departure whereby the same analytical framework is subject to impulses to the household's marginal utility of consumption. Under either Guo and Lansing's (1998) continuously progressive fiscal policy rule, or Dromel and Pintus' (2007) piece-wise linearly progressive tax scheme, we analytically show that an increase in the tax progressivity will always raise the economy's equilibrium degree of nominal-wage rigidity, and thus serve as an automatic stabilizer to alleviate the magnitude of cyclical fluctuations caused by preference disturbances. From a policy standpoint, our analysis illustrates that in the context of Kleven and Kreiner's (2003) model with imperfect competition and sticky nominal wages, whether a more progressive tax schedule (de)stabilizes the business cycle depends crucially on the driving source which leads to variations in macroeconomic aggregates. 


\section{References}

[1] Bencivenga, V.R. (1992), "An Econometric Study of Hours and Output Variation with Preference Shocks," International Economic Review 33, 449-471.

[2] Dromel, N.L. and P.A. Pintus (2007), "Linearly Progressive Income Taxes and Stabilization," Research in Economics 61, 25-29.

[3] Gabrovski, M. and J.-T. Guo (2019), "A Note on Progressive Taxation, Nominal Wage Rigidity, and Business Cycle Destabilization," forthcoming in Macroeconomic Dynamics.

[4] Guo, J.-T. and K.J. Lansing (1998), "Indeterminacy and Stabilization Policy," Journal of Economic Theory 82, 481-490.

[5] Kleven, H.J. and C.T. Kreiner (2003), "The Role of Taxes as Automatic Destabilizers in New Keynesian Economics," Journal of Public Economics 87, 1123-1136.

[6] Schmitt-Grohé, S. and M. Uribe, (1997). "Balanced-Budget Rules, Distortionary Taxes and Aggregate Instability," Journal of Political Economy 105, 976-1000. 


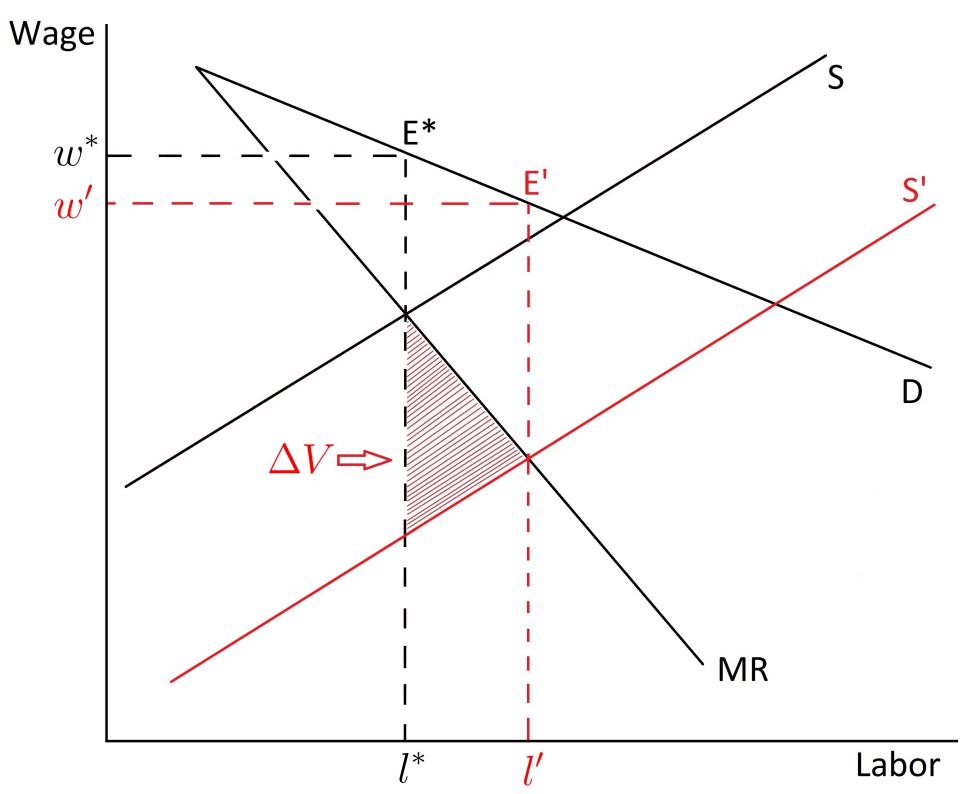

Figure 1: Labor Market under a Positive Preference Shock

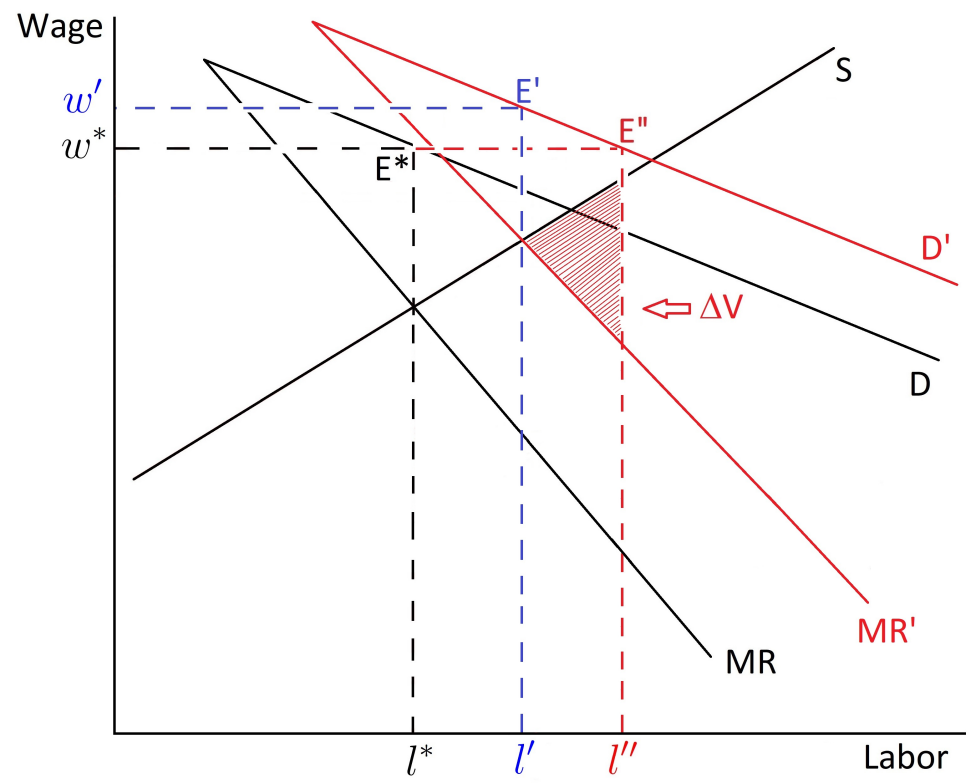

Figure 2: Labor Market under a Positive Monetary Shock 